\title{
ORIGINAL ARTICLE \\ The International Spinal Cord Injury Pain Extended Data Set (Version 1.0)
}

\author{
E Widerström-Noga ${ }^{1,2}$, F Biering-Sørensen ${ }^{3}$, TN Bryce ${ }^{4}$, DD Cardenas ${ }^{2}$, NB Finnerup ${ }^{5}$, MP Jensen ${ }^{6}$, \\ JS Richards ${ }^{7}$, EJ Richardson ${ }^{7}$ and PJ Siddall ${ }^{8,9}$
}

\begin{abstract}
Objectives: The objective of this study was to develop the International Spinal Cord Injury Pain Extended Data Set (ISCIPEDS) with the purpose of guiding the assessment and treatment of pain after spinal cord injury (SCI).

Setting: International.

Methods: The ISCIPEDS was reviewed by members of the International SCI Data Sets Committee, the International Spinal Cord Society Executive and Scientific Committees, American Spinal Injury Association and American Pain Society Boards, and the Neuropathic Pain Special Interest Group of the International Association for the Study of Pain, individual reviewers and societies.

Results: The working group recommended four assessment domains for the ISCIPEDS: (i) Pain symptoms including variables related to pain type, temporal course, severity, unpleasantness, tolerability of pain and questionnaires assessing pain type and symptom severity; (ii) Sensory signs to detect and quantify sensory abnormalities commonly associated with neuropathic pain, including dynamic mechanical and thermal allodynia, and hyperalgesia; (iii) Treatments (ongoing and past 12 months); and (iv) Psychosocial factors and comorbid conditions.

Conclusion: The ISCIPEDS was designed to be used together with the International SCI Pain Basic Data Set and provide a brief yet thorough assessment of domains related to chronic pain in individuals with $\mathrm{SCl}$. The data set includes pain-relevant self-reported assessments, questionnaires and sensory examinations. The recommendations were based on (i) their relevance to individuals with $\mathrm{SCl}$ and chronic pain, (ii) the existence of published findings supporting the utility of the selected measures for use in individuals with $\mathrm{SCl}$, and to the greatest extent possible (iii) their availability in the public domain free of charge.
\end{abstract}

Spinal Cord (2016) 54, 1036-1046; doi:10.1038/sc.2016.51; published online 12 April 2016

\section{INTRODUCTION}

Persistent and severe pain is common after a spinal cord injury $(\mathrm{SCI}),{ }^{1,2}$ and most individuals experience neuropathic and/or musculoskeletal pain at 1 year after injury. ${ }^{3}$ The persistence of pain after SCI often leads to higher levels of depression, ${ }^{4}$ significant psychosocial impact ${ }^{5-8}$ and reduced quality of life ${ }^{9}$ by interfering with sleep, mood and daily activities including social activities and work. ${ }^{10}$

Pain in people with SCI is classified in the broad categories nociceptive, neuropathic (at or below level of injury), other or unknown. ${ }^{11}$ The neuropathic pains are often associated with various sensory abnormalities including allodynia and hyperalgesia, ${ }^{12,13}$ and research suggests that assessment of these can help define phenotypes and/or predict pain development or treatment responses. ${ }^{3,14,15}$

The multidimensionality of pain is emphasized by the dynamic interaction between biological factors, psychological status, and social and cultural factors; this makes the pain experience highly individual and unique. Although biological factors may cause, maintain and modulate pain after SCI, psychological factors can exert a powerful influence on the perception and impact of pain, and social factors may modulate the impact and responses to these perceptions. ${ }^{16,17}$ Thus, the interrelationships between persistent pain, psychosocial factors, and physical and functional impairments underscore the importance of a multimodal approach to the assessment, treatment and rehabilitation of individuals who experience chronic pain after their SCI. ${ }^{18,19}$ The chronicity of pain associated with SCI also suggests that personal adaptation and coping skills are critical for achieving optimal quality of life after SCI. ${ }^{20,21}$

The International Spinal Cord Injury Pain Data Sets (ISCIPDSs) consist of a basic (ISCIPBDS) and an extended (ISCIPEDS) data set. The information collected in the ISCIPEDS should be considered supplemental to the information collected in the ISCIPBDS. The ISCIPBDS v2. $0^{22}$ contains a minimal amount of clinically relevant information concerning pain (for example, pain interference, probable pain diagnosis, location, intensity and duration of pain) that can be collected in the daily practice of health-care professionals with expertise in SCI. The ISCIPBDS v2.0 was shortened from its original format ${ }^{23}$ to increase its clinical utility and to reflect the new SCI pain taxonomy. ${ }^{11}$ The ISCIPBDS was adopted by the National Institute of

${ }^{1}$ The Miami Project to Cure Paralysis, University of Miami, Miller School of Medicine, Miami, FL, USA; ${ }^{2}$ Department of Physical Medicine and Rehabilitation, University of Miami, Miller School of Medicine, Miami, FL, USA; ${ }^{3}$ Clinic for Spinal Cord Injuries, Rigshospitalet, University of Copenhagen, Copenhagen, Denmark; ${ }^{4}$ Department of Rehabilitation Medicine, The Icahn School of Medicine at Mount Sinai, New York, NY, USA; ${ }^{5}$ Danish Pain Research Center, Department of Clinical Medicine, Aarhus University, Aarhus, Denmark; ${ }^{6}$ Department of Rehabilitation Medicine, University of Washington, Seattle, Washington, USA; ${ }^{7}$ Department of Physical Medicine and Rehabilitation, University of Alabama at Birmingham, Birmingham, AL, USA; ${ }^{8}$ Department of Pain Management, Greenwich Hospital, Hammond Care, Sydney, NSW, Australia and ${ }^{9}$ Sydney Medical School— Northern, University of Sydney, Sydney, Australia

Correspondence: Dr E Widerström-Noga, The Miami Project to Cure Paralysis, University of Miami, Miller School of Medicine, P.O. Box 016906 (R-48), Miami, FL 33101, USA. E-mail: EWiderstrom-Noga@med.miami.edu

Received 22 December 2015; revised 25 February 2016; accepted 12 March 2016; published online 12 April 2016 
Health, National Institute of Neurological Disorders and Stroke (NINDS) and Common Data Elements (CDEs) as a supplemental/ highly recommended data set to be collected in clinical SCI pain research (www.commondataelements.ninds.nih.gov/SCI.aspx\#tab = Data_Standards). ${ }^{24}$

The organization of the extended data set is directly based on the pain problems identified in the basic data set and is intended to be used in research studies and be collected by researchers or health-care professionals familiar with SCI. Data should be collected by interview (or the recommended mode of administration for a specific instrument) and by clinical examination. The ISCIPEDS was designed to evaluate the following domains: (i) Pain symptoms (for example, temporal course, severity, unpleasantness, tolerability and pain type). Pain symptoms are particularly important to evaluate in populations such as SCI, where pain is typically heterogeneous, persistent and often severe; (ii) Sensory signs to detect and quantify common sensory abnormalities associated with clinical pain (for example, abnormal responses to light touch, pinprick and cold sensation). The sensory measures were intentionally selected to be appropriate for bedside examination to facilitate their use. Identification of symptoms and signs associated with neuropathic pain may not only facilitate a better understanding of the clinical condition but may also provide a foundation for subgroup analyses in clinical trials and thus facilitate future mechanism-based treatment interventions; ${ }^{25,26}$ (iii) Treatments used currently or in the past 12 months (for example, dose (if appropriate), frequency, adverse effects and the person's rating of global impression of change). ${ }^{27}$ Information regarding a person's previous and current experience with various treatment interventions is vital for the planning of clinical studies and screening of potential participants for a clinical trial; (iv) Psychosocial domains and comorbid conditions including outcomes (for example, quality of life, satisfaction with life), mediating factors or comorbid conditions (for example, depression, anxiety).

Presently, the evidence base in the SCI pain research field does not strongly support the use of specific instruments above others. Therefore, the selection of specific instruments for a research study should primarily reflect a study's purpose and aims. The ISCIPEDS includes multiple measures for each domain with similar purposes and equivalent psychometric properties. However, for future revisions and updates of the ISCIPEDS, the utility of specific domains and instruments will be reevaluated as new evidence becomes available.

The overall purpose of the ISCIPDSs is to standardize the collection and reporting of pain in the SCI population and to encourage investigators in this field to assess several critical pain-related domains in research studies. Moreover, the use of comparable sets of outcome measures in research studies will increase efficiency and facilitate collaborations, translation, interpretation and application of results.

\section{MATERIALS AND METHODS}

The members of the interdisciplinary ISCIPDS working group have extensive experience in both the clinical management and the clinical research of pain associated with SCI. Each member was appointed by one of the four major organizations with a significant interest in this area of research (that is, International Spinal Cord Society (ISCoS), American Spinal Injury Association (ASIA), American Pain Society (APS) and International Association for the Study of Pain (IASP)). For the ISCIPEDS, one additional psychologist (ER) specializing in medical/clinical psychology and public health was added to the group.

The recommendations of instruments and methods were based on the criteria including (i) their relevance to individuals with SCI and chronic pain, (ii) the existence of published findings supporting the utility of the measures selected in samples of individuals with SCI, and to the greatest extent possible (iii) their availability in the public domain. Consistent with the development of the ISCIPBDS, ${ }^{22}$ the guiding principle was to prepare a data set that could be used without added cost by clinicians in various settings and countries and without the need of advanced technical equipment. To ensure consistency in the data collection and facilitate interpretation, detailed information is provided in a syllabus for each specific variable and response category. The development process of the ISCIPEDS followed the steps briefly outlined in Table 1.

\section{RESULTS}

The ISCIPEDS includes several important assessment domains that are divided into four sections.

\section{Pain symptoms}

This section is intended to assess individual variables related to the temporal course, severity, unpleasantness, tolerability of pain, as well as questionnaires related to the pain type and symptom severity.

Overall pain. These measures are not only intended to provide an overall assessment of pain (including all pain problems) but can also be used for individual pain problems (previously identified by the ISCIPBDS), if appropriate (Appendix A). This section includes the following items:

Number of days with pain in the last 7 days including today. This variable evaluates the constancy of pain by specifying the total number of days with pain during the last 7 days, including today, and the

\section{Table 1 Outline of the development of the final version of the International Spinal Cord Injury Pain Extended Data Set}

\section{Steps}

1 The working group of the International Spinal Cord Injury (SCI) Pain Data Set prepared the first version of the ISCIPEDS and a set of instructions (syllabus) primarily via e-mail discussions and also in face-to-face meetings at national and international meetings.

2 The ISCIPEDS was reviewed by members of the International SCI Data Sets Committee. The suggestions from the Committee members were discussed in the working group and appropriate changes made.

3 The ISCIPEDS was reviewed by Members of the International Spinal Cord Society (ISCoS) Executive and Scientific Committees and the American Spinal Injury Association (ASIA) Board. The comments from the Committees and Board members were discussed in the working group and further adjustments were made.

$4 \quad$ Organizations and Societies and individuals with an interest in SCI-related pain were also invited to review and comment on the ISCIPEDS. The data set was also posted on the ISCOS and ASIA websites for 2 months to allow additional comments and suggestions. The suggestions provided were discussed by the working group and adjustments were made.

5 The ISCIPEDS was reviewed by members of the American Pain Society (APS) Board and the Neuropathic Pain Special Interest Group (NeuPSIG) of the International Association for the Study of Pain (IASP). The comments from the Board and committee members were discussed in the working group and further adjustments were made.

6 To finalize the ISCIPEDS, members of the ISCoS Executive and Scientific Committees, and the ASIA Board reviewed the data set for final approval. 
response categories range from $0=$ none to $7=$ seven days. 'Today' is the day the individual answers the question regardless of the time of day. The duration of pain during the day is not relevant to this question.

Worst pain intensity in the last week. Pain intensity is the most common pain domain assessed in research and clinical settings. Although different rating scales have proven to be valid for assessing pain intensity, including the Numerical Rating Scale (NRS), the Verbal Rating Scale and the Visual Analog Scale, the 0-10 NRS has the most strengths and fewest weaknesses of available measures. ${ }^{28}$ Moreover, the $0-10$ NRS has been recommended by the IMMPACT consensus group for the use in pain clinical trials ${ }^{29}$ and by the 2006 NIDRR SCI pain outcome measures consensus group. ${ }^{30}$

The 7-day time frame was selected to balance the need to assess pain over a long enough epoch to capture usual pain, against the need to keep the time frame short enough to maximize recall accuracy. The instruction and end points used were designed to differentiate between pain intensity and pain unpleasantness. ${ }^{31}$ For example, the intensity of pain is related to how strong the pain feels and the unpleasantness of pain is related to how disturbing the pain is. To better understand the difference between pain intensity and unpleasantness, one can substitute the word 'sound' for 'pain'. Pain intensity is analogous to the loudness of a sound, whereas unpleasantness is analogous to the aversiveness of a sound not necessarily related to its loudness.

The worst pain intensity experienced during the last week is rated on a $0-10$ NRS (ranging from $0=$ 'No pain' to a maximum of $10=$ 'The most intense pain imaginable'). Please note that 'last week' specifically refers to the last 7 days including today.

Average pain unpleasantness in the last week. Pain is a result of sensory, cognitive and affective dimensions, and the emotional dimension can be evaluated separately from intensity. ${ }^{32}$ The average pain unpleasantness is rated on a $0-10$ NRS (ranging from $0=$ 'Not at all unpleasant' to a maximum of $10=$ 'The most unpleasant pain imaginable'). Please note that 'last week' specifically refers to the last 7 days including today.

Number of days with manageable/tolerable pain in the last 7 days including today. Manageable or tolerable pain is a construct reported by Zelman et al. ${ }^{33}$ and not specific to pain after SCI. Focus group methodology has suggested that manageable or tolerable pain is pain that permits concentration on something other than the pain, perhaps by using a treatment or self-remedy that 'takes the edge off pain and allows performance of daily activities or 'getting something done.' Other factors associated with manageable pain are lower levels of negative mood, feeling well enough to socialize and not experiencing excessive adverse effects of ongoing treatments including medication.

This variable specifies the total number of days with pain during the last 7 days, including today, and the response categories ranges from $0=$ none to $7=$ seven days. 'Today' is the day the individual answers the question regardless of the time of day. The duration of manageable/tolerable pain during the day is not relevant to this question.

Individual pain problems. These measures are intended to be performed for each separate pain problem identified in the ISCIPBDS (Appendix A).

Pain intensity in present moment. The present pain intensity for (up to) three pain problems (the three worst pain problems respondents experience) is rated on a 0-10 NRS (ranging from $0=$ 'No pain' to a maximum of $10=$ 'The most intense pain imaginable'). Please note that 'present' specifically refers to this moment.

How long does your pain usually last? This variable provides an estimate of the duration of pain. Some pain types are very brief and may be felt several times per day. This question refers to the duration of each separate pain event. Response categories are the following: $1 \mathrm{~min}$ or less; more than $1 \mathrm{~min}$ but less than $1 \mathrm{~h}$; at least $1 \mathrm{~h}$ but less than $24 \mathrm{~h}$; at least $24 \mathrm{~h}$ but not continuous; constant or continuous; and unknown. The duration of pain can be defined when a specific pain follows a predictable pattern. If no predictable pattern for a specific pain exists, the answer 'unknown' is given.

When during the day is the pain most intense? This variable identifies the diurnal peak in pain intensity. Response categories are the following: Morning, Afternoon, Evening, Night and Unpredictable; pain is not consistently more intense at any one time of day. 'Morning' is between $6.01 \mathrm{am}$ and Noon (06.01 and 12.00); 'Afternoon' is between Noon and $6.00 \mathrm{pm}$ (12.01 and 18.00); 'Evening' is between $6.01 \mathrm{pm}$ and Midnight (18.01 and 24.00); 'Night' is between Midnight and $6.00 \mathrm{am}$ (00.01 and 06.00).

Recommended questionnaires. These questionnaires are intended to provide supplemental information as appropriate for a specific purpose or interest (Table 2).

\section{Sensory signs}

These assessments are intended to detect and quantify common sensory abnormalities in a painful area at or below the level of injury (Appendix B). The sensory bedside assessment includes abnormal responses to light touch, pinprick and cold sensation compared with a non-affected control area above the level of injury. The sensory measures were intentionally selected to be appropriate for bedside examination and to detect and quantify sensory abnormalities, that is, mechanical allodynia (pain in response to an innocuous mechanical stimuli), mechanical hyperalgesia (exaggerated response to a painful mechanical stimulus) and thermal allodynia (pain in response to an innocuous thermal stimuli) commonly associated with neuropathic pain types.

Dynamic light touch. Dynamic light touch can be assessed by light stroking the skin with an innocuous moving stimuli, for example, a cotton wisp, cotton wool tip or a brush (for example, Somedic standardized brush, Sweden), of approximately $2 \mathrm{~cm}$ with a speed of $1-2 \mathrm{~cm} \mathrm{~s}^{-1} .{ }^{34}$ Sensation is rated as normal (compared with a control area in a non-affected skin area), absent (no sensation felt), hypoesthesia (decreased sensation compared with control area), hyperesthesia (increased sensation compared with control area), allodynia (light touch provokes pain) or other (changed sensation that cannot be categorized otherwise). If allodynia is present, the pain is rated on a $0-10$ NRS (ranging from $0=$ 'No pain' to a maximum of $10=$ 'Pain as bad as you can imagine').

Pinprick. Pinprick sensation can be assessed by pricking the skin with a disposable safety pin or calibrated monofilaments, for example, Semmes-Weinstein monofilaments or other custom-made weighted pinprick stimuli (Rolke et al. ${ }^{34}$ ). Pinprick is a nociceptive stimulus that normally evokes pain. Sensation is rated as normal when pain evoked in the painful area is no different than in the control area, absent when there is no evoked pain sensation, hypoalgesia when pain evoked in the painful area is less intense than in the control area, hyperalgesia when pain evoked in the painful area is more intense than in the control 


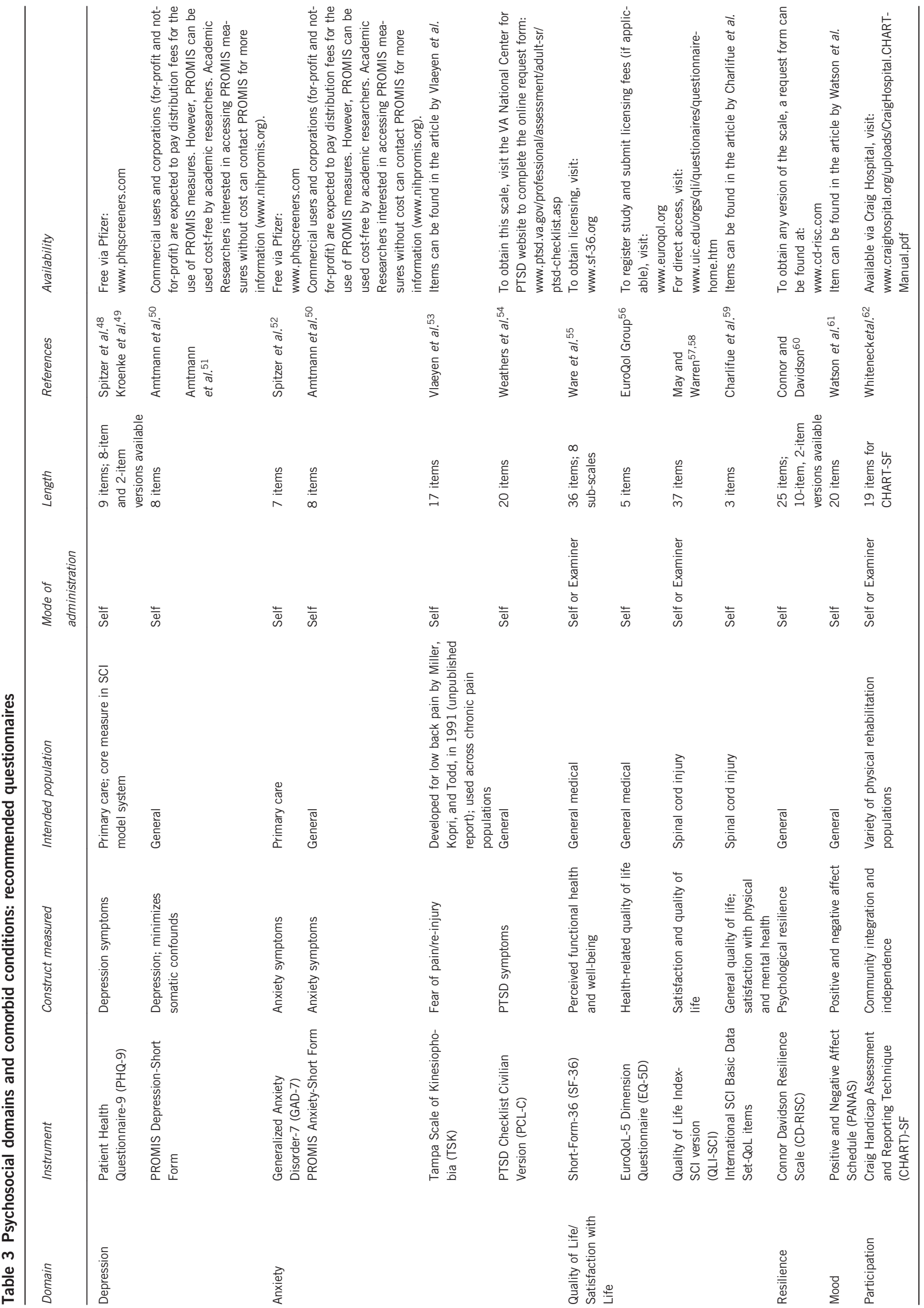


area, and other (changed sensation that cannot be categorized otherwise). If hyperalgesia is present, the pain is rated on a $0-10$ NRS (ranging from $0=$ 'No pain' to a maximum of $10=$ 'Pain as bad as you can imagine').

Cold. Cold sensation can be assessed using a cold thermoroller (Somedic Sweden) of 20 or $25^{\circ} \mathrm{C}$, a piece of cold metal or an acetone droplet. For determination of cold detection and cold pain thresholds, thermal tests can be performed using thermodes (TSA, Medoc, Israel or MSA, Somedic, Sweden); see Rolke et al. ${ }^{34}$ Sensation rated as normal (compared with a control area in a non-affected skin area), absent (no sensation felt), hypoesthesia (decreased sensation compared with control area), hyperesthesia (increased sensation compared with control area), allodynia (an innocuous cold stimuli provokes pain) or other (changed sensation that cannot be categorized otherwise). If allodynia is present, the pain is rated on a $0-10$ NRS (ranging from $0=$ 'No pain' to a maximum of $10=$ 'Pain as bad as you can imagine'). Because environmental temperature may affect skin temperature and thus thermal testing it is important to record the room temperature when testing.

\section{Treatments}

Information regarding a person's previous and current experience with various treatment interventions is important both for the planning of clinical studies and facilitates screening of potential participants for a clinical trial (Appendix C). The ISCIPEDS is designed to capture information regarding both past (last 12 months) and current treatments. Because of possible recall biases, the effectiveness of past treatments are not captured in detail but only whether a person has had the treatment in the past 12 months and if it was helpful or not, or unknown. For current, ongoing treatments, more details are captured, including the dose (if appropriate), frequency of treatment, any adverse effects and a rating of the person's global impression of change. $^{27}$

Past treatment. This variable specifies treatments for pain received in the past and treatment response. The respondent is to indicate ('Check') each treatment that they have received in the past for their pain. Where possible, the respondent also indicates whether it was helpful ('Yes') or not helpful ('No'). If the respondent cannot remember or is uncertain about effectiveness, they indicate 'Uncertain'. This section can be completed on one form to indicate treatments and responses for overall pain or on multiple forms for each specific pain type. Because of the fact that the management of pain in SCI is challenging with a wide range of treatments being tried that include pain medications - such as opioids, non-steroidal anti-inflammatory drugs, acetaminophen, tricyclic antidepressants and anticonvulsants-physical therapy and alternative treatment approaches - such as massage, marijuana, acupuncture and hypnosis, ${ }^{35-37}$ self-management, ${ }^{38}$ relaxation and psychotherapyand procedural and surgical interventions, the list provided is very long to cover the most common options.

Current treatment. This variable specifies the current treatments for pain, timing of treatment, response and side effects. The respondent is to indicate current treatments for pain including dose ('Dose'), if a medication, and frequency ('How often'). Effectiveness is assessed using the Patient Global Impression of Change ('PGIC'). ${ }^{27,30}$ Any side effects or adverse events ('Side effects/adverse events') related to the treatment are also to be noted. This section can be completed on one form to indicate treatments and responses for overall pain or on multiple forms for each specific pain.

\section{Psychosocial domains and comorbid conditions}

This section is intended to assess outcomes, mediating factors or comorbid conditions (for example, depression, anxiety, quality of life) (Table 3). The psychosocial domains that researchers should consider assessing in their studies of SCI pain include outcome variables, mediating variables and comorbid conditions that would be of interest to those seeking to develop, test or expand biopsychosocial models of SCI-related pain. The ISCIPEDS working group selected those domains and identified potential measures of those domains, as a function of (i) their relevance to individuals with SCI and chronic pain and (ii) the existence of published findings that support the utility of the measures selected in samples of individuals with SCI, and as much as possible (iii) their availability in the public domain.

\section{DISCUSSION}

There is a vast array of outcomes measures that have been recommended for use in neuropathic pain research ${ }^{39}$ and in SCI pain research specifically. ${ }^{30} \mathrm{~A}$ systematic review of all such measures is beyond the scope of the ISCIPEDS. Although not all of the recommended measures included in the ISCIPEDS were developed specifically for individuals with SCI, it was the consensus of the expert panel that the measures selected are those that would be most useful in SCI populations. More research will be needed to help establish their psychometric properties in individuals with SCI, and, pending the findings from this research, future recommendations may differ somewhat from our current ones. We recommend that researchers carefully examine the appropriateness of any measure they might consider using with respect to utility in the SCI chronic pain population. For example, standard measures for pain-related outcomes may have content that can be inappropriate for people with SCI (for example, pain intensity with walking) or that can be misleading if endorsed (for example, unusual sensory experiences). The instruments in the ISCIPEDS were selected in part to minimize that problem. The reader is also referred to the SCIRE (www.scireproject.com) and NINDS CDEs (www.commondataelements.ninds.nih.gov/SCI.aspx) websites where an extensive number of outcome measures are evaluated with respect to their applicability and psychometric properties. Although the measures reviewed in these loci are not focused only on pain per se, they offer other resources for SCI researchers who want to use the most valid scales, particularly those that are being proposed for adoption across studies.

\section{DATA ARCHIVING}

There were no data to deposit.

\section{CONFLICT OF INTEREST}

The authors declare no conflict of interest.

\section{ACKNOWLEDGEMENTS}

We thank the ISCoS, ASIA, and the APS Boards and the IASP NeuPSIG for endorsement and William Bauman, Susan Charlifue, Vanessa Noonan, Anoushka Singh, Michael Feehlings, Greg Nemuniatis and Lawrence Vogel for valuable comments and suggestions.

1 Cruz-Almeida Y, Martinez-Arizala A, Widerstrm-Noga EG. Chronicity of pain associated with spinal cord injury: A longitudinal analysis. J Rehabil Res Dev 2005; 42: 585.

2 Siddall PJ, McClelland JM, Rutkowski SB, Cousins MJ. A longitudinal study of the prevalence and characteristics of pain in the first 5 years following spinal cord injury. Pain 2003; 103: 249-257. 
3 Finnerup NB, Norrbrink C, Trok K, Piehl F, Johannesen IL, Sørensen JC et al. Phenotypes and predictors of pain following traumatic spinal cord injury: $A$ prospective study. J Pain 2014; 15: 40-48.

4 Wollaars MM, Post MWM, van Asbeck FWA, Brand N. Spinal cord injury pain: the influence of psychologic factors and impact on quality of life. Clin J Pain 2007; 23: 383-391.

5 Richards JS, Meredity RL, Nepomuceno C, Fine PR, Bennett G. Psycho-social aspects of chronic pain in spinal cord injury. Pain 1980; 8: 355-366.

6 Summers JD, Rapoff MA, Varghese G, Porter K, Palmer RE. Psychosocial factors in chronic spinal cord injury pain. Pain 1991; 47: 183-189.

7 Nicholson Perry K, Nicholas MK, Middleton J. Spinal cord injury-related pain in rehabilitation: A cross-sectional study of relationships with cognitions, mood and physical function. Eur J Pain 2009; 13: 511-517.

8 Kennedy P, Lude P, Taylor N. Quality of life, social participation, appraisals and coping post spinal cord injury: a review of four community samples. Spinal Cord 2006; 44: 95-105.

9 Middleton J, Tran Y, Craig A. Relationship between quality of life and self-efficacy in persons with spinal cord injuries. Arch Phys Med Rehabil 2007; 88: 1643-1648.

10 Widerström-Noga EG, Felipe-Cuervo E, Yezierski RP. Chronic pain after spinal injury: Interference with sleep and daily activities. Arch Phys Med Rehabil 2001; 82 1571-1577.

11 Bryce TN, Biering-Sørensen F, Finnerup NB, Cardenas DD, Defrin R, Lundeberg T et al. International Spinal Cord Injury Pain Classification: part I. Background and description. Spinal Cord 2012; 50: 413-417.

12 Eide PK, Jørum E, Stenehjem AE. Somatosensory findings in patients with spinal cord injury and central dysaesthesia pain. J Neurol Neurosurg Psychiatry 1996; 60: 411-415.

13 Finnerup NB, Johannesen IL, Sindrup SH, Bach FW, Jensen TS. Pain and dysesthesia in patients with spinal cord injury: A postal survey. Spinal Cord 2001; 39: 256-262.

14 Levitan Y, Zeilig G, Bondi M, Ringler E, Defrin R. Predicting the risk for central pain using the sensory components of the International Standards for Neurological Classification of Spinal Cord Injury. J Neurotrauma 2015; 32: 1684-1692.

15 Widerström-Noga E, Felix ER, Adcock JP, Escalona M, Tibbett J. Multidimensional neuropathic pain phenotypes after spinal cord injury. J Neurotrauma 2015; 33: 482-492.

16 Turk DC, Monarch ES. Biopsychosocial perspective on chronic pain. In: Turk DC, Gatchel RJ. (eds) Psychological Approaches to Pain Management: A Practitioner's Handbook. Guilford Press: New York, NY, USA, 1996; pp 3-29.

17 Jensen MP, Moore MR, Bockow TB, Ehde DM, Engel JM. Psychosocial factors and adjustment to chronic pain in persons with physical disabilities: a systematic review. Arch Phys Med Rehabil 2011; 92: 146-160.

18 Molton IR, Terrill AL, Smith AE, Yorkston KM, Alschuler KN, Ehde DM et al. Modeling secondary health conditions in adults aging with physical disability. J Aging Health 2014; 26: 335-359.

19 Craig A, Nicholson Perry K, Guest R, Tran Y, Dezarnaulds A, Hales A et al. Prospective study of the occurrence of psychological disorders and comorbidities after spinal cord injury. Arch Phys Med Rehabil 2015; 96: 1426-1434.

20 Haythornthwaite JA, Benrud-Larson LM. Psychological aspects of neuropathic pain. Clin J Pain 2000; 16: S101-S105

21 Molton IR, Stoelb BL, Jensen MP, Ehde DM, Raichle KA, Cardenas DD. Psychosocial factors and adjustment to chronic pain in spinal cord injury: replication and crossvalidation. J Rehabil Res Dev 2009; 46: 31.

22 Widerström-Noga E, Biering-Sørensen F, Bryce TN, Cardenas DD, Finnerup NB, Jensen MP et al. The International Spinal Cord Injury Pain Basic Data Set (version 2.0). Spinal Cord 2014; 52: 282-286.

23 Widerström-Noga E, Biering-Sørensen F, Bryce T, Cardenas DD, Finnerup NB, Jensen MP et al. The International Spinal Cord Injury Pain Basic Data Set. Spinal Cord 2008; 46: 818-823

24 Biering-Sørensen F, Alai S, Anderson K, Charlifue S, Chen Y, DeVivo M et al. Common data elements for spinal cord injury clinical research: a National Institute for Neurological Disorders and Stroke project. Spinal Cord 2015; 53: 265-277.

25 Baron R, Förster M, Binder A. Subgrouping of patients with neuropathic pain according to pain-related sensory abnormalities: a first step to a stratified treatment approach. Lancet Neurol 2012; 11: 999-1005.

26 Demant DT, Lund K, Vollert J, Maier C, Segerdahl M, Finnerup NB et al. The effect of oxcarbazepine in peripheral neuropathic pain depends on pain phenotype: $A$ randomised, double-blind, placebo-controlled phenotype-stratified study. Pain 2014; 155: 2263-2273.

27 Guy W. ECDEU Assessment Manual for Psychopharmacology, Revised. US Government Printing Office: Rockville, MD, USA. 1976.

28 Jensen MP, Karoly P Self-report scales and procedures for assessing pain in adults In: Turk DC, Melzack R (eds). Handbook of Pain Assessment, 2nd edn. The Guilford Press: New York, NY, USA. 2001; p 760.

29 Dworkin RH, Turk DC, Farrar JT, Haythornthwaite JA, Jensen MP, Katz NP et al. Core outcome measures for chronic pain clinical trials: IMMPACT recommendations. Pain 2005; 113: 9-19.

30 Bryce TN, Norrbrink C, Cardenas DD, Dijkers M, Felix ER, Finnerup NB et al. Pain after spinal cord injury: An evidence-based review for clinical practice and research. J Spinal Cord Med 2007; 30: 421-440.
31 Dannecker EA, George SZ, Robinson ME. Influence and stability of pain scale anchors for an investigation of cold pressor pain tolerance. J Pain 2007; 8: 476-482.

32 Price DD, Harkins SW, Baker C. Sensory-affective relationships among different types of clinical and experimental pain. Pain 1987; 28: 297-307.

33 Zelman DC, Smith MY, Hoffman D, Edwards L, Reed P, Levine E et al. Acceptable, manageable, and tolerable days: patient daily goals for medication management of persistent pain. J Pain Symptom Manage 2004; 28: 474-487.

34 Rolke R, Baron R, Maier C, Tölle TR, Treede RD, Beyer A et al. Quantitative sensory testing in the German Research Network on Neuropathic Pain (DFNS): Standardized protocol and reference values. Pain 2006; 123: 231-243.

35 Cardenas DD, Jensen MP. Treatments for chronic pain in persons with spinal cord injury: A survey study. J Spinal Cord Med 2006; 29: 109-117.

36 Murphy D, Reid DB. Pain treatment satisfaction in spinal cord injury. Spinal Cord 2001; 39: 44-46.

37 Norrbrink Budh C, Lundeberg T. Non-pharmacological pain-relieving therapies in individuals with spinal cord injury: A patient perspective. Complement Ther Med 2004; 12: 189-197.

38 Umlauf RL. Psychological interventions for chronic pain following spinal cord injury. Clin J Pain 1992; 8: 111-118.

39 Haanpää M, Attal N, Backonja M, Baron R, Bennett M, Bouhassira D et al. NeuPSIG guidelines on neuropathic pain assessment. Pain 2011; 152: 14-27.

40 Bouhassira D, Attal N, Alchaar H, Boureau F, Brochet B, Bruxelle J et al. Comparison of pain syndromes associated with nervous or somatic lesions and development of a new neuropathic pain diagnostic questionnaire (DN4). Pain 2005; 114: 29-36.

41 Hallström H, Norrbrink C. Screening tools for neuropathic pain: Can they be of use in individuals with spinal cord injury? Pain 2011; 152: 772-779.

42 Bryce TN, Richards JS, Bombardier CH, Dijkers MP, Fann JR, Brooks L et al. Screening for neuropathic pain after spinal cord injury with the Spinal Cord Injury Pain Instrument (SCIPI): A preliminary validation study. Spinal Cord 2014; 52: 407-412.

43 Jensen MP, Gammaitoni AR, Olaleye DO, Oleka N, Nalamachu SR, Galer BS. The Pain Quality Assessment Scale: Assessment of pain quality in carpal tunnel syndrome. J Pain 2006; 7: 823-832.

44 Dworkin RH, Turk DC, Revicki DA, Harding G, Coyne KS, Peirce-Sandner S et al. Development and initial validation of an expanded and revised version of the Short-form McGill Pain Questionnaire (SF-MPQ-2). Pain 2009; 144: 35-42.

45 Bouhassira D, Attal N, Fermanian J, Alchaar H, Gautron M, Masquelier E et al. Development and validation of the Neuropathic Pain Symptom Inventory. Pain 2004; 108: 248-257.

46 Krause SJ, Backonja M-M. Development of a Neuropathic Pain Questionnaire. Clin J Pain 2003; 19: 306-314.

47 Freynhagen R, Baron R, Gockel U, Tölle TR. painDETECT: A new screening questionnaire to identify neuropathic components in patients with back pain. Curr Med Res Opin 2006; 22: 1911-1920.

48 Spitzer RL, Kroenke K, Williams JB. Validation and utility of a self-report version of PRIME-MD: the PHQ primary care study. Primary Care Evaluation of Mental Disorders. Patient Health Questionnaire. JAMA 1999; 282: 1737-1744.

49 Kroenke K, Spitzer RL, Williams JB. The Patient Health Questionnaire-2. Med Care 2003; 41: 1284-1292.

50 Amtmann D, Cook KF, Johnson KL, Cella D. The PROMIS Initiative: Involvement of rehabilitation stakeholders in development and examples of applications in rehabilitation research. Arch Phys Med Rehabil 2011; 92: S12-S19

51 Amtmann D, Kim J, Chung H, Bamer AM, Askew RL, Wu S et al. Comparing CESD-10, PHQ-9, and PROMIS depression instruments in individuals with multiple sclerosis. Rehabil Psychol 2014; 59: 220-229.

52 Spitzer RL, Kroenke K, Williams JB, Löwe B. A brief measure for assessing Generalized Anxiety Disorder. Arch Intern Med 2006; 166: 1092.

53 Vlaeyen JW, Kole-Snijders AM, Boeren RG, van Eek H. Fear of movement/(re)injury in chronic low back pain and its relation to behavioral performance. Pain 1995; 62: 363-372.

54 Weathers FW, Litz BT, Keane TM, Palmieri PA, Marx BP, Schnurr PP The PTSD Checklist for DSM-5 (PCL-5). Natl Cent PTSD. 2013 www.ptsd.va.gov/professional/ assessment/adult-sr/ptsd-checklist.asp accessed 15 Dec 2015.

55 SF-36 Health Survey Manual and Interpretation Guide. New England Medical Center, The Health Institute: Boston, MA, USA. 1993.

56 EuroQol Group. EuroQol-a new facility for the measurement of health-related quality of life. Health Policy 1990; 16: 199-208.

57 May LA, Warren S. Measuring quality of life of persons with spinal cord injury: substantive and structural validation. Qual Life Res 2001; 10: 503-515.

58 May LA, Warren S. Measuring quality of life of persons with spinal cord injury: external and structural validity. Spinal Cord 2002; 40: 341-350.

59 Charlifue S, Post MW, Biering-Sørensen F, Catz A, Dijkers M, Geyh S et al. International Spinal Cord Injury Quality of Life Basic Data Set. Spinal Cord 2012; 50: 672-675.

60 Connor KM, Davidson JRT. Development of a new resilience scale: The ConnorDavidson Resilience Scale (CD-RISC). Depress Anxiety 2003; 18: 76-82.

61 Watson D, Clark LA, Tellegen A. Development and validation of brief measures of positive and negative affect: the PANAS scales. J Pers Soc Psychol 1988; 54: 1063-1070.

62 Whiteneck GG, Charlifue SW, Gerhart KA, Overholser JD, Richardson GN. Quantifying handicap: A new measure of long-term rehabilitation outcomes. Arch Phys Med Rehabil 1992; 73: 519-526. 


\section{APPENDIX A}

\section{PAIN SYMPTOMS}

\section{A. Overall pain}

Number of days with pain in the last 7 days including today

$$
\text { none; } 1 ; 2 ; \quad 3 ; 4 ; 5 ; 6 ; \quad 7 ; \text { unknown }
$$

Worst pain intensity in the last week

$0=$ no pain $; 10=$ the most intense pain imaginable:

$$
0 ; \quad 1 ; \quad 2 ; \quad 3 ; \quad 4 ; \quad 5 ; \quad 6 ; \quad 7 ; \quad 8 ; \quad 9 ; 10
$$

Average pain unpleasantness in the last week

$0=$ not at all unpleasant; $10=$ the most unpleasant pain imaginable
$0 ; \quad 1 ; \quad 2 ; \quad 3 ; \quad 4 ; \quad 5 ; \quad 6 ; \quad 7 ; \quad 8 ; \quad 9 ; \quad 10$

Number of days with manageable/tolerable pain in the last 7 days including today

$$
\text { none; } 1 ; 2 ; \quad 3 ; 4 ; 5 ; 6 ; \quad 7 ; \text { unknown }
$$

\section{B. Individual pain problems}

Pain intensity in present moment

$0=$ no pain $; 0=$ the most intense pain imaginable:
0
; $2 ; 3 ;$
$4 ; 5$
6
$6 ; \quad 7 ; \quad 9 ; \quad 10$

How long does your pain usually last?

$\leq 1 \mathrm{~min} ; \quad>1 \mathrm{~min}$ but $<1 \mathrm{hr} ; \quad \geq 1 \mathrm{hr}$ but $<24 \mathrm{hrs} ; \quad \geq 24 \mathrm{hrs} ; \quad$ constant or continuous; unknown

When during the day is the pain most intense?

$\square$ morning (06.01-12.00); $\square$ afternoon (12.01-18.00); $\square$ evening (18.01-24.00); $\square$ night (00.01-06.00)

$\square$ unpredictable (pain is not consistently more intense at any one time of day) 


\section{APPENDIX B}

\section{SENSORY SIGNS}

\section{Dynamic light touch}

At level of injury

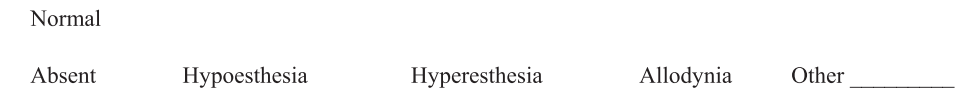

If allodynia, rate the intensity: $0 ; 1 ; 2 ; 3 ; 4 ; 5 ; 6 ; 7 ; 8 ; 9 ; 10$

Below level of injury

Normal

Absent Hypoesthesia Hyperesthesia Allodynia Other

If allodynia, rate the intensity: $0 ; 1 ; 2 ; 3 ; 4 ; 5 ; 6 ; 7 ; 8 ; 9 ; 10$

Notes: Left or right side can be noted here

\section{Pinprick}

At level of injury

Normal

Absent Hypoalgesia Hyperalgesia Other

If hyperalgesia, rate the intensity: $0 ; 1 ; 2 ; 3 ; 4 ; 5 ; 6 ; 7 ; 8 ; 9 ; 10$

Below level of injury

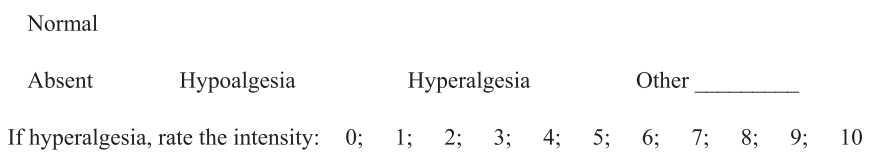

Notes: Left or right side can be noted here

\section{Cold}

At level of injury

$\begin{array}{llll}\text { Normal } & & & \\ \text { Absent } & \text { Hypoesthesia } & \text { Hyperesthesia } & \text { Allodynia Other }\end{array}$

If allodynia, rate the intensity: $0 ; 1 ; 2 ; 3 ; 4 ; 5 ; 6 ; 7 ; 8 ; 9 ; 10$

$\underline{\text { Below level of injury }}$
Normal
Absent
Hypoesthesia
Hyperesthesia
Allodynia Other
If allodynia, rate the intensity:
$0 ; \quad 1 ; \quad 2 ; \quad 3 ; \quad 4 ; \quad 5 ; \quad 6 ; \quad 7 ; \quad 8 ; \quad 9 ; \quad 10$

Notes: Left or right side can be noted here 


\section{APPENDIX C}

\section{TREATMENTS}

Past treatments

This section can either be filled out for overall pain or for each separate pain component.

Please indicate previous treatments (over the last 12 months) and whether the treatment was helpful.

\begin{tabular}{|c|c|c|c|c|}
\hline \multicolumn{2}{|c|}{ Please indicate all treatments you have had (over the last 12 months) } & \multicolumn{3}{|c|}{ Was the treatment helpful? } \\
\hline Check & & Yes & No & $\begin{array}{l}\text { Uncertain/ } \\
\text { Unknown }\end{array}$ \\
\hline & Physiotherapy & & & \\
\hline & Aerobic exercise (low to moderate intensity) & & & \\
\hline & $\begin{array}{l}\text { Passive exercise (non-weight bearing or against resistance, e.g., } \\
\text { stretching) }\end{array}$ & & & \\
\hline & Resistance exercise (strength building, e.g., weight training) & & & \\
\hline & Position adjustment (in wheelchair, bed, etc.) & & & \\
\hline & Joint mobilisation/manipulation (incl. chiropractic, osteopathic) & & & \\
\hline & Other, specify & & & \\
\hline & Passive and stimulation therapy & & & \\
\hline & Massage & & & \\
\hline & Acupressure & & & \\
\hline & Transcutaneous electrical nerve stimulation (TES, TNS, TENS) & & & \\
\hline & Ultrasound & & & \\
\hline & Laser & & & \\
\hline & Heat therapy (incl. heat-packs, shortwave) & & & \\
\hline & Other, specify & & & \\
\hline & Relaxation and Psychotherapy & & & \\
\hline & Bio-feedback/relaxation training & & & \\
\hline & $\begin{array}{l}\text { Relaxation (relaxation techniques, e.g., muscle relaxation or deep } \\
\text { breathing) }\end{array}$ & & & \\
\hline & Meditation (meditation techniques, e.g., concentrative, religious) & & & \\
\hline & Mindfulness meditation (meditation using mindfulness technique) & & & \\
\hline & Hypnosis & & & \\
\hline & Cognitive/Behavioural therapy & & & \\
\hline & Other psychotherapy & & & \\
\hline & Other, specify & & & \\
\hline & Oral and topical medication & & & \\
\hline & Antidepressants (e.g., amitriptyline, nortriptyline, duloxetine) & & & \\
\hline & Antiepileptics (e.g., pregabalin, gabapentin, carbamazepine) & & & \\
\hline & Tramadol & & & \\
\hline & Opioids (e.g., morphine, oxycodone, buprenorphine, fentanyl) & & & \\
\hline & Cannabinoids (e.g., marijuana) & & & \\
\hline & Acetaminophen/paracetamol & & & \\
\hline & NSAIDs/aspirin e.g., ibuprofen, naproxen, celecoxib, meloxicam & & & \\
\hline & Benzodiazepines e.g., diazepam & & & \\
\hline
\end{tabular}




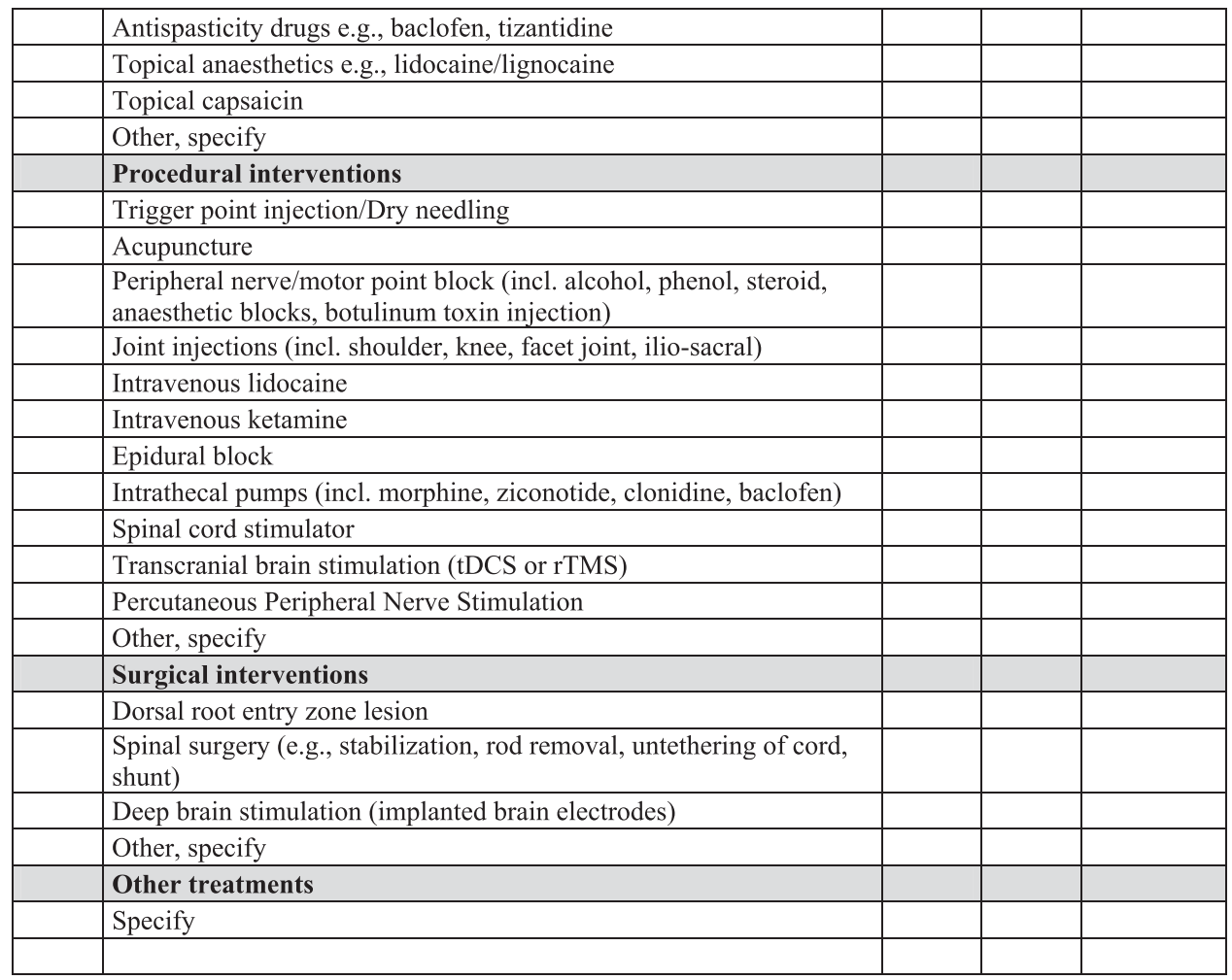

Current treatments: For examples of treatments please see previous section (Past treatments)

\begin{tabular}{|l|l|l|l|l|}
\hline Treatment & Dose & How often & PGIC* & Side effects/adverse events \\
\hline & & & & \\
\hline & & & & \\
\hline & & & & \\
\hline & & & & \\
\hline & & & & \\
\hline & & & & \\
\hline
\end{tabular}

*PGIC - Patient Global Impression of Change Indicate the effect of the treatment on your global wellbeing using one of the following descriptors:

Very much improved (1) - Much improved (2) - Minimally improved (3) - No change (4) -

Minimally worse (5) - Much worse (6) - Very much worse (7) 